\title{
DESENVOLVIMENTO DE UM NOVO PROCESSO DE PURIFICAÇÃO DO POLISSACARÍDEO CAPSULAR DE STRPTOCOCCUS PNEUMONIAE SOROTIPO 14
}

\author{
R. T. ZANARDO, D. B. FIGUEIREDO, S. KRASCHOWETZ, J. CABRERA-CRESPO, V. M. \\ GONÇALVES
}

Instituto Butantan, Centro de Biotecnologia

E-mail para contato: rafazanardo@usp.br

\begin{abstract}
RESUMO - O principal fator de virulência do $S$. pneumoniae é o polissacarídeo (PS) capsular, antígeno das vacinas atuais elaboradas com PS purificados de sorotipos prevalentes na população. Neste trabalho foi desenvolvido um processo de purificação escalonável do PS do sorotipo 14, responsável por 39\% das doenças em crianças de 0-6 anos no Brasil. Após separação celular por microfiltração tangencial, o caldo contendo PS foi concentrado por ultrafiltração tangencial $(50 \mathrm{kDa})$. Além das já descritas precipitações alcoólicas $20 \%$ e $60 \%, 2$ novas estratégias foram testadas para remoção contaminantes: precipitação com ácido tricloroacético (TCA) e diafiltração em presença do detergente docecil sulfato de sódio (SDS) para facilitar o escape de contaminantes no ultrafiltrado. TCA e SDS foram eficientes, sobretudo para eliminação de proteínas e SDS aumentou a eficiência das precipitações alcoólicas. A pureza requerida foi atingida com a combinação de SDS, TCA e precipitações alcoólicas e a recuperação global de PS ficou em $50 \%$.
\end{abstract}

\section{INTRODUÇÃO}

S. pneumoniae ou "pneumococo" é uma bactéria Gram-positiva, encapsulada, disposta aos pares (diplococos) ou em cadeias curtas, nutricionalmente fastidiosa e de metabolismo anaeróbio aerotolerante (Cartwright, et al 1994). S. pneumoniae é um patógeno exclusivamente humano, encontrado normalmente na microbiota da nasofaringe e responsável por infecções das vias respiratórias superiores e inferiores, que podem ser moderadas (otite, sinusite, bronquite e pneumonia) ou graves (pneumonia necrotizante, meningite, bacteremia e septicemia), levando muitas vezes os pacientes a óbito (Bricks; Berezin, 2006).

A cápsula polissacarídica forma a estrutura externa do pneumococo, é capaz de inibir a fagocitose e o principal fator de virulência deste microrganismo, uma vez que cepas sem cápsula são fagocitadas e não causam doenças. Outra propriedade da cápsula é estimular a produção de anticorpos que podem ser utilizados para classificar o pneumococo em sorotipos. Sabe-se que cada sorotipo corresponde a uma estrutura química diferente do polissacarídeo (PS) da cápsula e 
que cada um deles inibe a fagocitose com maior ou menor intensidade, o que resulta em uma habilidade diferenciada de cada sorotipo para causar a doença pneumocócica (Henrichsen, 1995).

Dentre os 93 sorotipos conhecidos do microrganismo, o sorotipo 14 faz parte dos que são prevalentes no Brasil, sendo responsável por 39\% da doença pneumocócica na faixa etária de 0-6 anos e por 10,8\% dos casos da doença em crianças de 6-14 anos (Organização Pan-Americana de Saúde, 2007), sendo assim, a produção do polissacarídeo do sorotipo 14 (PS14) é de extrema importância para compor uma vacina pneumocócica para imunização da população brasileira.

O processo de purificação do PS pode ser entendido como a eliminação de proteínas, ácidos nucleicos e outras impurezas contidas no caldo de células. Os processos descritos para purificação de PS capsulares utilizados como vacinas são compostos por uma série de precipitações seletivas com etanol e/ou detergente catiônico (brometo de cetiltrimetilamônio), seguidas de centrifugações e ultracentrifugações contínuas e desproteinização com fenol (Gotschlich et al,1969; Frasch, 1990), cromatografia e tratamento enzimático. Uma vez que as etapas de purificação são responsáveis por $20 \%$ a $80 \%$ do valor total da produção de um bioproduto, o desenvolvimento de novas estratégias de purificação é importante para a reduzir o custo de produção e viabilizar a obtenção de uma vacina para distribuição gratuita à população.

\section{OBJETIVOS}

O objetivo deste trabalho foi desenvolver um método de purificação de PS14 proveniente de diferentes lotes de caldo fermentado de $S$. pneumoniae sorotipo 14 de forma alcançar os requerimentos de pureza exigidos em relação ao conteúdo proteico $(\leq 3 \%)$ e de ácidos nucleicos $(\leq 2 \%)(\mathrm{WHO}, 2005)$.

\section{MATERIAIS E MÉTODOS}

\subsection{Microrganismo}

O microrganismo utilizado foi S. pneumoniae sorotipo 14, cepa 5287 fornecida pela sessão de Bacteriologia do Instituto Adolfo Lutz, previamente selecionada devido à maior produção de PS14 (Gogola et al., 2012).

\subsection{Cultivo e separação inicial}

Os cultivos foram feitos no Laboratório de Bioprocessos do Instituto Butantan pela aluna de mestrado Anne Letícia Silva Ferri. Após o processo de fermentação, o caldo fermentado foi inativado com $0,05 \%(\mathrm{p} / \mathrm{v})$ de timerosal durante uma noite. A purificação iniciou-se com a remoção das células por centrifugação ou microfiltração tangencial $0,22 \mu \mathrm{m}$, dependendo do 
volume do caldo. O microfiltrado foi concentrado em membrana de ultrafiltração tangencial de corte de $50 \mathrm{kDa}$. Lavagens com diferentes tampões foram realizadas para remover as moléculas menores que $50 \mathrm{kDa}$, como moléculas de substrato e produtos do metabolismo. O concentrado foi armazenado a $-20^{\circ} \mathrm{C}$ e usado para as etapas de purificação subsequentes, que envolvem passos independentes para que ocorra o enriquecimento de PS14 e a eliminação de proteínas e ácidos nucleicos.

\subsection{Purificação do PS}

A partir do concentrado $50 \mathrm{kDa}$, duas estratégias de purificação foram avaliadas, conforme mostra o Esquema 1.

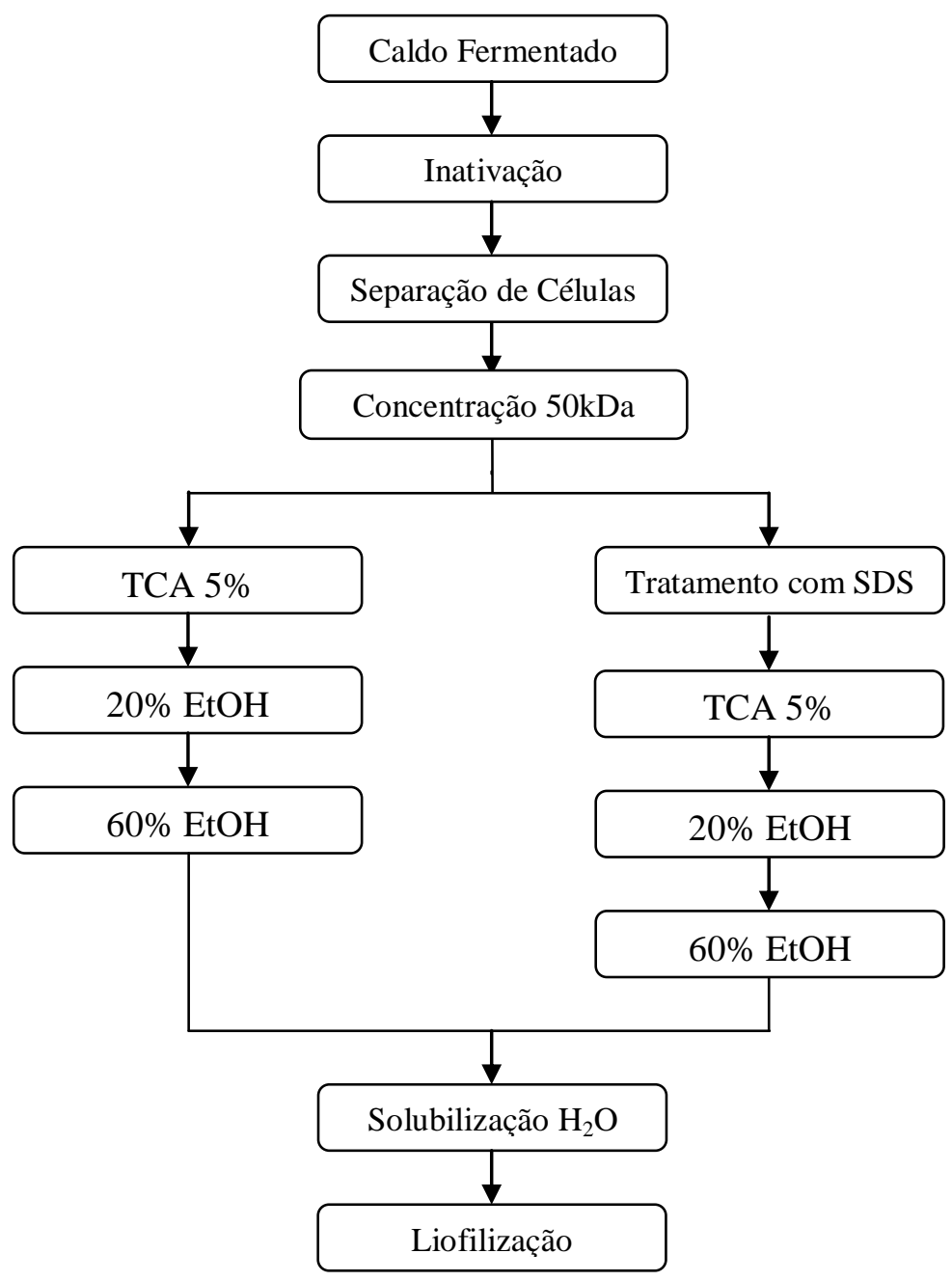

Esquema 1: Fluxograma do processo de purificação avaliado. 


\section{Precipitacão de impurezas com ácido tricloroacético a 5\% (TCA5\%)}

TCA a $5 \%(\mathrm{v} / \mathrm{v})$ foi empregado para precipitar proteínas (Saeed; Thomassen, 1982). TCA foi adicionado ao concentrado 50kDa e a mistura ficou em banho de gelo por $30 \mathrm{~min}$. Logo após, a amostra foi centrifugada a $17.696 \mathrm{~g}$, a $4{ }^{\circ} \mathrm{C}$ por $1 \mathrm{~h}$. O sobrenadante contendo PS14 foi então rapidamente neutralizado com $\mathrm{NaOH} 5 \mathrm{M}$ (pH final entre 6-7).

\section{Tratamento com dodecil sulfato de sódio (SDS) a $0,5 \%$}

SDS em uma concentração de $0,5 \%(\mathrm{p} / \mathrm{v})$ seguido de ácido etilenodiamino tetracético (EDTA) $2 \mathrm{mM}$ e tampão Tris $25 \mathrm{mM}$ pH 7,0 foram utilizados sequencialmente na diafiltração a volume constante do concentrado de $50 \mathrm{kDa}$, todos em uma quantidade de seis vezes o volume do concentrado.

\section{Precipitacão alcoólica a 20\%}

Primeiramente acetato de sódio $5 \%(\mathrm{p} / \mathrm{v})$ foi adicionado à fração contendo PS14. O pH foi ajustado para 5,4 com ácido acético e então etanol $20 \%(\mathrm{v} / \mathrm{v})$ adicionado sob agitação. A precipitação aconteceu a $4^{\circ} \mathrm{C}$ por $18 \mathrm{~h}$, a amostra foi centrifugada a $17.696 \mathrm{~g}$ e $4{ }^{\circ} \mathrm{C}$ por 45 min e o precipitado, representado em sua maioria por proteínas e ácidos nucleicos, eliminado.

\section{Precipitacão alcoólica a $60 \%$}

Ao sobrenadante da precipitação alcoólica a $20 \%$ foi primeiramente adicionado acetato de sódio de forma a obter-se uma concentração final de $8 \%(\mathrm{p} / \mathrm{v}) . \mathrm{O} \mathrm{pH}$ foi ajustado para 5,8 com ácido acético e então etanol foi adicionado sob agitação até a concentração final de $60 \%$ (v/v). Após $18 \mathrm{~h} \mathrm{a} 4{ }^{\circ} \mathrm{C}$, a amostra foi centrifugada nas mesmas condições da etapa anterior.

\section{Solubilizacão em água}

O produto da precipitação alcoólica a $60 \%$ foi solubilizado em água sob agitação por $18 \mathrm{~h}$ a $20^{\circ} \mathrm{C}$. O material foi centrifugado a $17.696 \mathrm{~g}$ e $4{ }^{\circ} \mathrm{C}$ por $45 \mathrm{~min}$ para retirar ácidos nucleicos e proteínas que ficaram irreversivelmente desnaturados em decorrência do tratamento alcoólico e o PS14 purificado foi obtido no sobrenadante.

\section{Liofilizacão}

O PS14 purificado foi congelado a $-80^{\circ} \mathrm{C}$ e liofilizado para a retirada de água (liofilizador ModulyoD 115 - Freeze Dryer, Thermo Electron Corporation).

\section{Métodos analíticos}

PS14 foi medido por ELISA de captura (Gogola et al., 2012), a concentração de proteínas totais foi determinada pelo método de Lowry et al (1951) utilizando albumina de soro bovino 
(BSA) como padrão e a concentração de ácidos nucleicos foi medida pela absorbância a 260nm considerando 1 unidade Abs260nm igual a $50 \mu \mathrm{g} / \mathrm{mL}$ de ácidos nucleicos.

\section{RESULTADOS E DISCUSSÃO}

\section{Estratégia de Purificação 1 (TCA $5 \%$ )}

O uso do TCA 5\% logo após a concentração em membrana de ultrafiltração tangencial de $50 \mathrm{kDa}$ em conjunto com as precipitações alcoólicas removeram $98 \%$ das proteínas presentes no material inicial (Tabela 1). Os ácidos nucleicos foram eliminados em sua maioria na etapa de precipitação alcoólica a $60 \%$ (96\% em relação ao concentrado 50kDa, Tabela 1). Apesar da eficiência da eliminação de ambos os contaminantes e uma ótima recuperação de PS14 (81\%), esta estratégia não permitiu alcançar os níveis de pureza exigidos para ácidos nucleicos ( $\leq$ $2 \%(\mathrm{p} / \mathrm{p})$ em relação à massa de PS14) e os níveis de pureza para proteína ficaram bem próximos do limite exigido $(\leq 3 \%(\mathrm{p} / \mathrm{p})$ em relação à massa de PS14). Além disso, pode-se notar que o TCA $5 \%$ interferiu na determinação da concentração dos contaminantes, subestimando os resultados (Tabela 1).

Tabela 1: Resultados do processo de purificação usando TCA 5\% para precipitação do concentrado $50 \mathrm{kDa}$

\begin{tabular}{|c|c|c|c|c|c|c|c|c|}
\hline Amostra & $\begin{array}{c}\text { Volume } \\
\text { (ml) }\end{array}$ & $\begin{array}{c}\text { PS14 } \\
\text { Total } \\
\text { (mg) }\end{array}$ & $\begin{array}{c}\text { Nucleicos } \\
\text { Total } \\
\text { (mg) }\end{array}$ & $\begin{array}{c}\text { Proteinas } \\
\text { Total } \\
\text { (mg) }\end{array}$ & $\begin{array}{c}\text { Rendimento } \\
\text { Global }\end{array}$ & $\begin{array}{c}\text { Rendimento } \\
\text { por Etapa }\end{array}$ & $\begin{array}{c}\text { Proteina } \\
\text { por } \\
\text { PS14 }\end{array}$ & $\begin{array}{c}\text { \% de Ac } \\
\text { Nucleicos } \\
\text { por PS14 }\end{array}$ \\
\hline [50kDa] & 625 & 124,3 & 105,9 & 425,4 & $100 \%$ & $100 \%$ & $342,1 \%$ & $85,2 \%$ \\
\hline TCA 5\% & 630 & 129,5 & 79,4 & 36,0 & $104 \%$ & $104 \%$ & $27,8 \%$ & $61,3 \%$ \\
\hline $\begin{array}{c}\text { Sobrenadante } \\
\mathbf{2 0} \%\end{array}$ & 870 & 111,5 & 79,4 & 61,9 & $90 \%$ & $86 \%$ & $55,6 \%$ & $71,3 \%$ \\
\hline $\begin{array}{c}\text { Solubilizado } \\
\mathbf{6 0} \%\end{array}$ & 300 & 100,3 & 3,4 & 2,9 & $\mathbf{8 1 \%}$ & $90 \%$ & $\mathbf{2 , 8 \%}$ & $3,4 \%$ \\
\hline
\end{tabular}

Diante desses resultados, foi elaborada a segunda estratégia de purificação incluindo o tratamento com SDS durante a diafiltração em membrana de 50kDa, seguido então da precipitação com TCA 5\% e das precipitações alcoólicas já estabelecidas.

\section{Estratégia de Purificação 2 (SDS + TCA 5\%)}

O SDS é um detergente aniônico e foi empregado para facilitar a eliminação de componentes de baixa massa molecular através da membrana de $50 \mathrm{kDa}$. Além disso, tal como observado na Tabela 2, o SDS parece ter contribuído para desnaturar as proteínas e separar as 
fitas de DNA e assim facilitar a precipitação destes compostos com etanol a $20 \%$ na etapa seguinte. Apesar de a recuperação do PS14 (50\%) não ter sido tão elevada quanto a da estratégia de purificação $1(81 \%)$, devido principalmente às perdas do PS14 através da membrana de $50 \mathrm{kDa}$, a estratégia de purificação 2 permitiu alcançar a pureza requerida tanto para proteínas $(1,4 \%)$ como para ácidos nucleicos $(1,8 \%)$.

Tabela 2: Resultados do processo de purificação usando SDS durante a diafiltração e TCA $5 \%$ para precipitação do concentrado $50 \mathrm{kDa}$

\begin{tabular}{|c|c|c|c|c|c|c|c|c|}
\hline Amostra & $\begin{array}{c}\text { Volume } \\
\text { (ml) }\end{array}$ & $\begin{array}{c}\text { PS14 } \\
\text { Total } \\
\text { (mg) }\end{array}$ & $\begin{array}{c}\text { Proteinas } \\
\text { Total } \\
\text { (mg) }\end{array}$ & $\begin{array}{c}\text { Ac. } \\
\text { Nucleicos } \\
\text { Total } \\
(\mathbf{m g})\end{array}$ & $\begin{array}{c}\text { Rendimento } \\
\text { Global }\end{array}$ & $\begin{array}{c}\text { Rendimento } \\
\text { por Etapa }\end{array}$ & $\begin{array}{c}\text { \% de } \\
\text { Proteina } \\
\text { por } \\
\text { PS14 }\end{array}$ & $\begin{array}{c}\text { \% de Ac } \\
\text { Nucleicos } \\
\text { por PS14 }\end{array}$ \\
\hline $\begin{array}{c}\text { [50kDa] + } \\
\text { Salina }\end{array}$ & 625 & 160,0 & 446,6 & 140,0 & $100 \%$ & $100 \%$ & $279,0 \%$ & $87,5 \%$ \\
\hline [50kDa] + SDS & 150 & 85,7 & 304,3 & 62,2 & $54 \%$ & $54 \%$ & $355,3 \%$ & $72,6 \%$ \\
\hline TCA 5\% & 155 & 77,6 & 0,6 & 11,3 & $48 \%$ & $91 \%$ & $0,7 \%$ & $14,6 \%$ \\
\hline $\begin{array}{c}\text { Sobrenadante } \\
\mathbf{2 0} \%\end{array}$ & 222 & 82,0 & 4,7 & 10,2 & $51 \%$ & $106 \%$ & $5,7 \%$ & $12,4 \%$ \\
\hline $\begin{array}{c}\text { Solubilizado } \\
\mathbf{6 0} \%\end{array}$ & 140 & 80,8 & 1,1 & 1,5 & $\mathbf{5 0 \%}$ & $99 \%$ & $\mathbf{1 , 4} \%$ & $\mathbf{1 , 8 \%}$ \\
\hline
\end{tabular}

\section{CONCLUSÃO}

Os dois processos de purificação atingiram a pureza requerida para proteínas, porém apenas a estratégia de purificação combinando diafiltração com SDS 0,5\% e precipitação com TCA 5\% possibilitou alcançar o valor exigido para ácidos nucleicos.

Mais estudos são necessários para estabelecer métodos para quantificar os componentes da amostra sem interferência do TCA 5\% e para aumentar o rendimento final do PS14.

A estratégia de purificação 2 permitiu a obtenção do PS14 nas condições exigidas para a produção de uma vacina pneumocócica.

\section{REFERENCIAS}

BRICKS, L.F.; BEREZIN, E. Impact of Pneumococcal Conjugate Vaccine on the Prevention of Invasive Pneumococcal Diseases. J. Pedriatr., v. 82, n. 3, p. S67-S74, 2006.

CARTWRIGHT, C.P.; STOCK F.; GILL, V.J.; Improved enrichment broth for cultivation of fastidious organisms. J. Clin. Microbiol., 32 (7):1825-1826, 1994.

FRASCH, C.E. Production and control of Neisseria meningitides vaccines. In: Bacterial vaccines (Ed.Alan R. Liss). Inc. New York, pp. 123 145, 1990. 
GOGOLA, V.M.R.; et al.; Quantification of capsular polysaccharide os Strptococcus penumoniae serotype 14 in culture broth samples. Anal. Biochem.; v. 421, p. 250-255, 2012.

GOTSCHLICH, E.C.; LIU, T.Y.; ARTENSTEIN, MS, Human immunity to the meningococcus. J. Exp. Med. 129, 1349-1 365, 1969.

HENRICHSEN, J. Six Newly Recognized Types of Streptococcus pneumoniae. Journal of Clinical Microbiology. v. 33, n. 10, p. 2759-62, 1995.

LOWRY, O. H.; Rosenbrough, N. J.; Farr, R. H. Protein measurement with Folin phenol reagent. J. Biol. Chem., v.193, p.265-275, 1951.

Organização Pan-Americana de Saúde (OPAS), Informe Regional de Sireva II - Datos por País y por Grupos de Edad sobre las Características de los Aislamientos de Streptococcus pneumoniae, Haemophilus influenzae y Neisseria meningitidis, en procesos invasores, 20002005. Documentos Técnicos. Tecnologías Esenciales de Salud, 2007.

SAEED, K.; THOMASSEN, Y.; Electrothermal atomic absorption spectrometric determination of selenium in blood serum and seminal fluid after protein precipitation with trichloroacetic acid. Analytica Chimica Acta, vol. 143, p 223-228, 1982.

WORLD HEALTH ORGANIZATION (WHO). Recommendations for the production and control of pneumococcal conjugate vaccines. WHO Technical Report Series, n. 927, Annex 2, 2005. 